\title{
Effectiveness of Mobile Phone Reminders in Improving Adherence and Treatment Outcomes of Patients on Art in Adamawa State, Nigeria: A Ramdomized Controlled Trail
}

\author{
Kabiru Usman Suru ${ }^{1 *}$, J E Chiegil ${ }^{1}$, S O Adeyemi ${ }^{2}$, O F Martins ${ }^{2}$ \\ ${ }^{1}$ Department of Public Health, Texila American University Guyana \\ ${ }^{2}$ Department of Public Health, Federal Medical Centre Yola, Adamawa State, Nigeria
}

\begin{abstract}
Adherence to antiretroviral therapy (ART) among people living with human immunodeficiency virus (PLHIV) is very imperative in achieving successful treatment outcome and decreased risk of HIV transmission to uninfected people. This is a randomized controlled trial study conducted in Adamawa State, Nigeria. 244 patients were randomized to intervention or control group. Data obtained from the study was analyzed using SPSS Version 21. Frequencies distributions, descriptive statistics were presented, Inferential statistics such as Pearson Chi square, McNemar's test, Paired T test, correlation and repeated measures ANOVA were used to measure the strength of associations and relationships between the various variables and probability of statistically significant level set $<0.05$ at $95 \%$ Confidence interval. The response rates in the intervention and control groups were $99 \%$ and $96.7 \%$ at 3 months; $97.5 \%$ and $92.6 \%$ at 6 months, respectively. Individual socio-demographic characteristics were not found to be associated with adherence levels in this study. At six months follow up the proportion of the respondents who had good adherence (>95\%) was higher (89.1\%) and statistically significant $(p=0.001)$ in the intervention group compared to control group $(63.1 \%)$ and $(p=0.617)$. A significantly higher frequency in missed clinic appointments $(7.98 \mathrm{vs} 1.68)(p=0.024)$ was noticed in the control group, and a statistically significant increase in the proportion of participants who reported an increase in weight $(p=0.001), C D 4$ cells counts $(p=0.001)$ and decrease in the presence of tuberculosis and other opportunistic infections were observed among patients in the intervention group.
\end{abstract}

Keywords: Adherence, Antiretroviral Therapy (ART), CD4 cell count, Nigeria, People Living with HIV (PLWH).

\section{Introduction}

The HIV/AIDS pandemic remains a major public health problem worldwide, more especially in sub-Saharan Africa. About 36.9 million people are living with HIV/AIDS globally as at 2017 , of which $69.93 \%$ reside in African countries [1]. Nigeria has the second highest burden of people living with HIV (PLHIV) in the world after South Africa [2]. As of 2017 about 3.1 million people are currently estimated to be living with HIV in Nigeria, and about 880,668 PLHIV are receiving treatment, (34\% and $24 \%$ of Adult and children living with HIV are on ART) [1]. According to UNAID report in 2018, approximately 150,000 people died from AIDS-related illnesses in Nigeria in 2017 [1]. Adamawa state with Yola as capital is located in the northeastern region of Nigeria and has a prevalence of $2.5 \%$. This is comparatively lower than the neighboring states Taraba and Gombe which have a prevalence of $5.2 \%$ and $3.4 \%$ respectively [3] and higher than Borno State which is $1.1 \%$ [3].

The goal of HIV treatment is to reduce HIVassociated morbidity and mortality, restored and preserved immunologic function, sustain viral suppression, and prevent transmission of HIV infection and subsequently prolonged duration of survival. But unfortunately, maintaining adequate levels of adherence to antiretroviral medications has become a challenge to many people living with HIV, and even healthcare providers, because a failing regimen as a result of poor adherence leads to increased opportunistic infections, increased hospitalization, and outpatient visits, thereby increasing the workload to health care providers. Inadequate adherence to treatment is also associated with decrease CD4 counts, increase 
detectible viral loads, disease progression, frequent reoccurrence of opportunistic infections, and deteriorating health outcomes [4].

According to $\mathrm{WHO}, 95 \%$ minimum adherence is required to achieve treatment success [5]. Although the roll-out of antiretroviral therapy significantly reduced human immunodeficiency virus related morbidity and mortality, access and adequate adherence to treatment are needed to achieve good clinical outcomes [6]. However, in Nigeria this is still a major problem due to problem of poor adherence to ART. In one of the studies conducted in Nigeria, adherence level among the PLWHIV on ART was just $73.4 \%$ [7]. Forgetfulness, too busy to remember, wanting to avoid side effects, lack of social support, negative perceptions, poor communication with providers, stigma and discrimination, non-disclosure of status and pills burden are some of the major contributing factors to the non-adherence to ART.

Mobile phones present a promising means to improve patient adherence and health outcomes. Though, there is finite information on the effect of mobile phones for health programs on ART adherence or the behavior change processes through which such interventions may improve patient health outcome [8]. Poor adherence to antiretroviral therapy is a critical challenge in achieving good HIV treatment outcome in Nigeria. It results in suboptimal viral suppression, increase viral replication, emergence of drug resistance, treatment failure and loss of future treatment options [9]. Therefore, it is very imperative to ensure strict adherence to Antiretroviral (ARV) medications to achieve sustained HIV viral suppression, reduced risk of drug resistance, improved overall health, quality of life, and survival, as well as decreased risk of HIV transmission to uninfected people. This will also reduce the need for more frequent, complicated regimens which are relatively expensive and add more burden to both patients and government [9]. Monitoring people on antiretroviral therapy (ART) is important to ensure successful treatment, identify adherence problems, and determine whether to switched ART regimen or not in case of treatment failure.

With the rapid increase of PLWHIV commenced on ART due to rapid expansion of ART centers and the implementation of the 2016 National Guidelines for HIV prevention treatment and care in Nigeria, which recommended test and start, the possibility of poor retention to ART may likely be higher if nothing is done to strengthen adherence among PLWHIV. The use of mobile phones to remind the clients on their appointment schedule in country with more than 80 million people using mobile phone may possibly improve the retention of clients on Antiretroviral treatment. This research is also consistent with current PEPFAR and WHO guidelines recommendation on mobile phone text messages, or SMS, reminders to promote ART adherence among HIV-positive patients on ART [10, 11]. However, its utilization is low in many resource limited countries, including Nigeria. Although many studies have been carried out worldwide on the effectiveness of mobile phone reminders on adherence and patient retention, little is available in the literature concerning such works in northeastern Nigeria, hence the decision to carry out this study.

This study aimed to evaluate the effectiveness of mobile phone reminders and patient tracking in improving medication adherence, clinic attendance, retention to care and clinical outcomes of anti-retroviral therapy among PLWHIV enrolled in to care and treatment at selected hospital in Adamawa, Nigeria.

\section{Methods}

A randomized control clinical trial study was conducted in five selected comprehensive Antiretroviral Therapy (ART) sites located across the three geo-political zone in Adamawa state, Nigeria (Federal Medical Centre (FMC) Yola, State Specialist Hospital Yola, St Francis Hospital Jambutu in Yola, General hospital Mubi and General hospital Mayo Belwa), to assess the effectiveness of mobile phone reminders and patient tracking on adherence, retention and clinical outcomes among clients on anti-retroviral therapy. This study was conducted from November 2017 to May 2018. The study population were all adult HIVpositive patients who were enrolled in to care and initiated on ART three month before the study at the ART clinics in Federal medical centre Yola, Specialist hospital Yola, St Francis Hospital Yola, General Hospital Mubi and General hospital Mayo Belwa, based on the Nigeria 2016 National Guidelines for HIV prevention treatment and care. Clients from 18 years and above initiated on ART for at least 
three months before the study in ART clinic at five selected sites with valid telephone numbers, able to read text messages were included in the study. While clients less than 18 years, less than 3 months on ART, restarting ART due to previous history of defaulting, Pregnant patients and clients transferred inn from other facilities were excluded from the study.

Sample size estimation: The sample size was calculated using the formula below [12].

$$
n=\frac{\left\{Z_{1-\alpha} / 2 \sqrt{2 \bar{P}(1-\bar{P})}+Z_{1-\beta} \sqrt{\left(P_{1}\left(1-P_{1}\right)+P_{2}\left(1-P_{2}\right)\right.}\right\}}{2}
$$

The largest sample size was obtained for the outcome variable of adherence to Antiretroviral therapy. For an estimated improvement in adherence to antiretroviral therapy.

Where:

$\mathrm{P}_{1}=0.95$ (Desired level of adherence to ART)

$\mathrm{P}_{2}=0.81$ (Shittu RO, et al. 2013) Baseline

$$
\begin{gathered}
\overline{\mathrm{P}}=\mathrm{P}_{1}+\mathrm{P}_{2} / 2=0.95+\frac{0.81}{2}=\frac{1.76}{2}=0.88 \\
\mathrm{Z}_{1-\alpha / 2}=1.96 \text { at } 95 \% \mathrm{CI} \\
\mathrm{Z}_{1-\beta}=1.282 \text {, at } 90 \% \text { power }
\end{gathered}
$$

$$
\begin{gathered}
n=\frac{\{1.96 \sqrt{2 \times 0.88 \times(1-0.88}+1.282 \sqrt{0.95(1-0.95)+0.81(1-0.81)}\}^{2}}{(0.95-0.81)^{2}} \\
n=\frac{\{1.96 \sqrt{0.2112}+1.282 \sqrt{0.0475+0.1539}\}^{2}}{0.14^{2}} \\
=\frac{\{0.9+0.575\}^{2}}{0.0196} \\
n=1766
\end{gathered}
$$

$n=111 \times 2=222,10 \%$ attrition $=22$.

Total $=222+22=244$.

The clinic ART patients' registers containing the list of all HIV-positive patients initiated on ART based on the 2016 Nigeria, national guideline for HIV prevention treatment and care from August 2017 to October 2017 at the five selected recruitment sites was used as the sampling frame.

A simple random sampling method was used to select the eligible clients for the study from the study population. Color-coded cards were used to allocate participants to intervention and control group. A total of 244 color coded cards put in separate sealed opaque envelopes (122 green cards represented intervention group; 122 white cards represented the control group). Client could pick a single envelope one by one under the supervision of the trained research assistants. The research assistant opened the sealed envelope and used the colour code to know which group the client belonged and so determined who received the intervention and who did not base on their chosen colour. A single blinded technique was used with clients not knowing which group they belonged to the respondents in both the control and intervention group received routine adherence counselling session, clinical symptoms, TB status screening, Opportunistic infections screening, weight measurement at baseline, 3 months and 6 months, CD4 count was measured at based line and 6 months. In addition to these standard cares the intervention group received a minimum of three (at based line, 3 and month 6) individual counselling sessions with the research assistants lasting an average of 10 minutes per encounter, weekly text message medication reminder, text message reminders 3 days before scheduled clinic appointments and phone call a day to appointment scheduled by the trained research assistants for the period of six months. The clients who did not show up for their medication refills were tracked by the trained research assistant. 


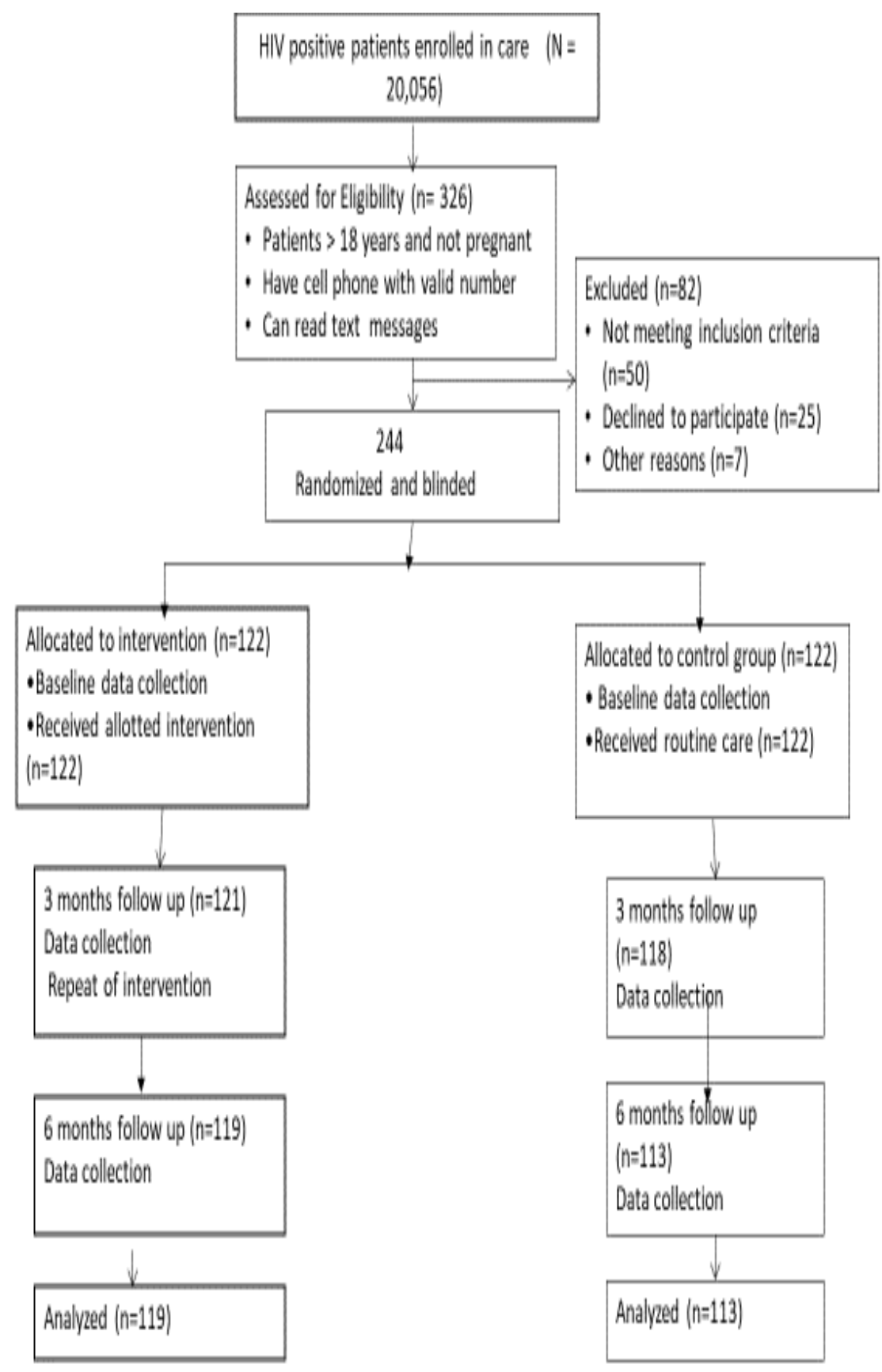

Figure 1. Flow Diagram of Patient Participants in a Randomized Clinical Trial Conducted among HIV Positive Patient in 5 Selected Comprehensive ART Sites in Adamawa State, Nigeria

The primary and secondary data for both the control and intervention groups were collected at baseline, 3 months and 6 months using a standard adherence questionnaire and approved hospital client's medical records tools. Data obtained from the study was coded and entered into Statistical Package for Social Sciences (SPSS) Version 21. The data was checked and cleared for double entry and outliers before analysis was done. The data analysis was conducted using frequencies distributions, descriptive statistics (means, standard deviation, standard error of mean). Inferential statistics such as Pearson Chi square, McNemar's test and correlation were used to determine associations and relationships. The confidence interval was set at $95 \%$ for mean estimations. The level of significance; alpha $(\alpha)$ was set at 0.05 . A decision rule to reject the null hypothesis when $p$ is less than 0.05 .

Ethical Consideration: Ethical clearance was obtained from the Adamawa State Ministry of 
Health, Department of Research and Statistics, Ethical Committee. A written and signed informed consent was obtained from each participant before he or she was enrolled into the study.

\section{Results}

A total of two hundred and forty-four (244) HIV-positive patients were recruited from five HIV/AIDS clinics providing comprehensive Antiretroviral Therapy (ART) in Adamawa State and participated in the study. At baseline, the intervention and control groups had an equal number of 122 participants each. The response rates in the intervention and control groups were 99\% and $96.7 \%$ at 3 months; $97.5 \%$ and $92.6 \%$ at 6 months, respectively. Out of the five patients lost in the two groups, only one was lost to follow up in the intervention group while in the control group, two were lost to follow up and two died. By the 6-month follow-up period, three participants had died, three transferred to other facilities while six were lost to follow up.

\section{Baseline Socio-demographic Characteristics of the Respondents}

Most of the respondents were middle aged with the highest proportion of $37.7 \%$ within the 36 - 45 years age grouping in the intervention group and $39.3 \%$ within the $26-35$ years age grouping in the control group. A higher proportion of the participants were females in both the intervention (64.8\%) and control (63.1\%) groups (Table 1). About a third of the participants had a tertiary educational degree in both groups and half were married and Christians (Table 1). More of the respondents were from the smaller ethnic groups (intervention $=60.7 \%$; control $=64.8 \%$ ) and were self-employed (intervention $=34.4 \%$ control $=41.8 \%)$ (Table 1). More people reported to have monthly income between $\mathrm{N} 5,000$ and $\mathrm{N} 20,000$ and residing in urban areas in both the intervention and control groups (Table 1).

Table 1. Baseline Distribution of Socio-demographic Characteristics of Respondents in Intervention and Control Groups

\begin{tabular}{|c|c|c|c|c|c|}
\hline \multirow[t]{2}{*}{ Variables } & \multirow{2}{*}{\multicolumn{2}{|c|}{ Intervention }} & \multicolumn{2}{|c|}{ Control } & \multirow[t]{2}{*}{ p-value } \\
\hline & & & $\mathbf{N o}^{0}$ & & \\
\hline \multicolumn{6}{|l|}{ Age } \\
\hline $18-25$ & 9 & 7.4 & 11 & 9.0 & \multirow[t]{4}{*}{$0.822^{\mathrm{a}}$} \\
\hline $26-35$ & 43 & 35.2 & 48 & 39.3 & \\
\hline $36-45$ & 46 & 37.7 & 40 & 32.8 & \\
\hline$>45$ & 24 & 19.7 & 23 & 18.9 & \\
\hline \multicolumn{6}{|l|}{ Gender } \\
\hline Male & 43 & 35.2 & 45 & 36.9 & \multirow[t]{2}{*}{$0.790^{\mathrm{b}}$} \\
\hline Female & 79 & 64.8 & 77 & 63.1 & \\
\hline \multicolumn{6}{|l|}{ Marital Status } \\
\hline Single & 28 & 23.0 & 29 & 23.8 & \multirow[t]{5}{*}{$0.984^{\mathrm{a}}$} \\
\hline Married & 63 & 51.6 & 66 & 54.1 & \\
\hline Separated & 11 & 9.0 & 10 & 8.2 & \\
\hline Divorced & 7 & 5.7 & 6 & 4.9 & \\
\hline Widow/Widower & 13 & 10.7 & 11 & 9.0 & \\
\hline \multicolumn{6}{|l|}{ Religion } \\
\hline Christianity & 66 & 54.1 & 64 & 52.5 & \multirow[t]{2}{*}{$0.797^{\mathrm{b}}$} \\
\hline Islam & 56 & 45.9 & 58 & 47.5 & \\
\hline \multicolumn{6}{|l|}{ Education } \\
\hline Non-formal & 24 & 19.7 & 24 & 19.7 & $0.992^{\mathrm{a}}$ \\
\hline Primary & 19 & 15.6 & 19 & 15.6 & \\
\hline Secondary & 36 & 29.5 & 38 & 31.1 & \\
\hline Tertiary & 43 & 35.2 & 41 & 33.6 & \\
\hline \multicolumn{6}{|l|}{ Ethnicity } \\
\hline Fulani & 31 & 25.4 & 29 & 23.8 & $0.774^{\mathrm{a}}$ \\
\hline
\end{tabular}




\begin{tabular}{|l|l|l|l|l|l|}
\hline Hausa & 17 & 13.9 & 14 & 11.5 & \\
\hline Others & 74 & 60.7 & 79 & 64.8 & \\
\hline Employment Status & 32 & 26.2 & 29 & 23.8 & $0.686^{\text {a }}$ \\
\hline Unemployed & 42 & 34.4 & 51 & 41.8 & \\
\hline Self-employed & 39 & 32.0 & 35 & 28.7 & \\
\hline Civil Servant & 9 & 7.4 & 7 & 5.7 & \\
\hline Others \\
\hline Residential Location \\
\hline Rural & 39 & 32.0 & 37 & 30.3 & $0.954^{\text {a }}$ \\
\hline Semi-Urban & 35 & 28.7 & 35 & 28.7 & \\
\hline Urban & 48 & 39.3 & 50 & 41.0 & \\
\hline Monthly Income (Naira) & 31 & 25.4 & 29 & 23.8 & $0.856^{\text {a }}$ \\
\hline$<5,000$ & 50 & 41.0 & 55 & 45.1 & \\
\hline $5000-20000$ & 21 & 17.2 & 22 & 18.0 & \\
\hline $20000-50000$ & 20 & 16.4 & 16 & 13.1 & \\
\hline$>50000$ &
\end{tabular}

${ }^{a}$ p-value obtained by Chi-Square Test

${ }^{b}$ p-value obtained by McNemar's

$*$ Sig at $\mathrm{p}<0.05$

\section{Analysis of Effectiveness of Intervention on Medication Adherence}

A repeated measures analysis was performed to determine the effect of the intervention on the groups and the interaction between the groups.

In the intervention group, a statistically significant increase in percentage was observed between the baseline and 6-month time periods (Table 2). There was an increase of $19.4 \%$ in the proportion of respondents who had a good level of adherence to medication between baseline and 6 months $(\mathrm{p}<0.001)$. Meanwhile, in the control group, the proportion of participants with good adherence level to medication decreased by $14.8 \%$ (Table 3). This change in the levels was not statistically significant $(\mathrm{p}=0.617)$.

Between the 3 months and 6-months periods in the intervention group, there was a $4.7 \%$ increase in the proportion of participants who had a good level of adherence to medications (Table 2). The change in the level of adherence between the two time periods was statistically significant $(\mathrm{p}<0.001)$. In the control group, there was a decrease in the percentage of people who adhered to their medications by $6.6 \%$.

Table 2. Change in the Level of Adherence Following Intervention in the Intervention Group

\begin{tabular}{|l|l|l|l|l|}
\hline Medication Adherence & \multicolumn{2}{|l|}{ Frequency n (\%) } & Change in \% & p-value \\
\hline & Baseline & 3-month follow up & & \\
\hline Poor (> 80\%) & $4(3.3)$ & $0(0.0)$ & & \\
\hline Fair $(80-95 \%)$ & $33(27.0)$ & $18(14.8)$ & & \\
\hline Good (> 95\%) & $85(69.7)$ & $103(84.4)$ & 14.7 & $0.001^{\text {a } *}$ \\
\hline Total & $122(100)$ & $121(99.2)$ & & \\
\hline & Baseline & 6-month follow up & & \\
\hline Poor (> 80\%) & $4(3.3)$ & $0(0.0)$ & & \\
\hline Fair $(80-95 \%)$ & $33(27.0)$ & $13(10.7)$ & & $0.001^{\text {a* }}$ \\
\hline Good (>95\%) & $85(69.7)$ & $106(89.1)$ & 19.4 & \\
\hline Total & $122(100)$ & $119(97.5)$ & & \\
\hline & 3-month follow up & 6-month follow up & & \\
\hline Poor $(>80 \%)$ & $0(0.0)$ & $0(0.0)$ & & $0.001^{\text {a* }}$ \\
\hline Fair $(80-95 \%)$ & $18(14.8)$ & $13(10.7)$ & & \\
\hline Good $(>95 \%)$ & $103(84.4)$ & $106(89.1)$ & 4.7 & \\
\hline Total & $121(99.2)$ & $119(97.5)$ & & \\
\hline
\end{tabular}

${ }^{a} p$ value was calculated using McNemar's Test

*significant at $<0.05$ 
Table 3: Change in the Level of Adherence Following Intervention in the Control Group

\begin{tabular}{|l|l|l|l|l|}
\hline \multirow{2}{*}{ Medication Adherence } & \multicolumn{2}{|l|}{ Frequency } & Change in \% & \multirow{2}{*}{ p-value } \\
\cline { 2 - 3 } & N $(\%)$ & & \\
\hline & Baseline & 3-month follow up & & \\
\hline Poor $(>80 \%)$ & $7(5.7)$ & $6(4.9)$ & & \\
\hline Fair $(80-95 \%)$ & $20(16.4)$ & $27(22.1)$ & & \\
\hline Good (> 95\%) & $95(77.9)$ & $85(69.7)$ & -8.2 & $0.774^{\text {a }}$ \\
\hline Total & $122(100)$ & $121(99.2)$ & & \\
\hline & Baseline & 6-month follow up & & \\
\hline Poor $(>80 \%)$ & $7(5.7)$ & $4(3.3)$ & & \\
\hline Fair $(80-95 \%)$ & $20(16.4)$ & $32(26.2)$ & & \\
\hline Good $(>95 \%)$ & $95(77.9)$ & $77(63.1)$ & -14.8 & \\
\hline Total & $122(100)$ & $113(92.6)$ & & \\
\hline & $\mathbf{3 - m o n t h}$ follow up & $\mathbf{6 - m o n t h}$ follow up & & \\
\hline Poor $(>80 \%)$ & $6(4.9)$ & $4(3.3)$ & & \\
\hline Fair $(80-95 \%)$ & $27(22.1)$ & $32(26.2)$ & & \\
\hline Good $(>95 \%)$ & $85(69.7)$ & $77(63.1)$ & -6.6 & \\
\hline Total & $121(99.2)$ & $113(92.6)$ & & \\
\hline
\end{tabular}

ap value was calculated using McNemar's Test

* significant at $<0.05$

\section{Analysis of Effectiveness of Intervention on Clinic Attendance}

At three months, out of the total participants in the intervention group (121), only 4(3.3) participants missed their clinic appointment while 9 participants (7.63) missed their clinic appointment in the control group. While at six months, out of the total participants in the intervention group (119), only 2 (1.68) participants missed their clinic appointment while 9 participants (7.9.8) missed their clinic appointment in the control group (Table 4).

The intervention had a positive change in the frequency of clinic appointments among the HIV patients in Adamawa State. The results that there was an equal proportion of participants (117) who did not miss their clinic appointments at 3 months in the intervention group. The proportion was maintained across the time periods (Table 5). After 3 months, one participant was lost to follow up in the intervention group and 3 after 6 months. In the control group, 4 and 9 participants were lost to follow up or died at 3 months and 6 months respectively. The proportion of participant who missed clinic appointment in the control group reduced from $109(89.3 \%)$ to 104 $(85.2 \%)$ in the control group (Table 6).

Table 4. Distribution of Participants' Missed Clinic Appointment in Intervention and Control Group

\begin{tabular}{|l|l|l|l|l|l|l|}
\hline Outcome: Missed Clinic Appointment & Intervention & Control & \multicolumn{2}{l|}{ p-value } \\
\cline { 2 - 6 } & $\mathbf{N} \%$ & N \% & \multicolumn{2}{l|}{} \\
\hline 3 Months & 117 & 96.69 & 109 & 92.37 & $0.141^{\text {a }}$ \\
\hline No & 4 & 3.3 & 9 & 7.63 & \\
\hline Yes & $\mathbf{1 2 1}$ & $\mathbf{1 0 0}$ & $\mathbf{1 1 8}$ & $\mathbf{1 0 0}$ & \\
\hline Total & 117 & 98.32 & 104 & 92.04 & \multirow{2}{*}{$0.024^{\text {a* }}$} \\
\hline 6 Months & 2 & 1.68 & 9 & 7.96 & \\
\hline No & $\mathbf{1 1 9}$ & $\mathbf{1 0 0}$ & $\mathbf{1 1 3}$ & $\mathbf{1 0 0}$ & \\
\hline Yes &
\end{tabular}

${ }^{a}$ p-value calculated by McNemar's test

*Significant at $\mathrm{p}<0.05$ 
Table 5. Change in Missed Clinic Attendance in the Intervention Group

\begin{tabular}{|l|l|l|l|l|}
\hline \multirow{2}{*}{ Items } & \multicolumn{2}{|l|}{ Frequency } & Change in \% & p-value \\
\cline { 2 - 5 } & N $(\%)$ & & \\
\hline Missed Clinic Appointment & 3-month follow up & 6-month follow up & & \\
\hline No & $117(95.9)$ & $117(95.9)$ & 0.00 & $1.000^{\mathrm{a}}$ \\
\hline Yes & $4(3.3)$ & $2(1.6)$ & 1.5 & \\
\hline Lost to follow up/death/transfer & $1(0.8)$ & $3(2.5)$ & 1.7 & \\
\hline Total & $\mathbf{1 2 2}(\mathbf{1 0 0})$ & $\mathbf{1 2 2}(\mathbf{1 0 0})$ & & \\
\hline
\end{tabular}

${ }^{a} \mathrm{p}$-value calculated by McNemar's test

*Significant at $\mathrm{p}<0.05$

Table 6. Change in Missed Clinic Attendance in the Control Group

\begin{tabular}{|l|l|l|l|l|}
\hline \multirow{2}{*}{ Items } & \multicolumn{2}{|l|}{ Frequency } & Change in \% & \multirow{2}{*}{ p-value } \\
\cline { 2 - 3 } & N (\%) & & \\
\hline Missed Clinic Appointment & 3-month follow up & 6-month follow up & & \\
\hline No & $109(89.3)$ & $104(85.2)$ & 4.1 & $1.000^{\text {a }}$ \\
\hline Yes & $9(7.4)$ & $9(7.4)$ & 0.0 & \\
\hline Lost to follow up/death/transfer & $4(3.3)$ & $9(7.4)$ & -4.1 & \\
\hline Total & $\mathbf{1 2 2}(\mathbf{1 0 0})$ & $\mathbf{1 2 2}(\mathbf{1 0 0})$ & & \\
\hline
\end{tabular}

a $\mathrm{p}$ value was calculated using McNemar's Test

*significant at $<0.05$

\section{Analysis of Effectiveness of Intervention on Clinical Outcome}

The change in clinical outcome of the HIV patients was measured by evaluating the following variables: weight, CD4 cell count, presence of tuberculosis and other opportunistic infections. A statistically significant increase in the proportion of participants who reported an increase in weight, CD4 cells counts and a decrease in the presence of tuberculosis and other opportunistic infections is an indication of the effectiveness of the intervention.

\section{Changes in Weight Following Intervention}

The change in the participants' weight between the baseline to 3-month follow-up; baseline to 6-month follow-up and 3-month and 6-month follow up periods were statistically significant $(\mathrm{p}<0.001)$ in the intervention group (Table 7). However, in the control group, the change observed between the baseline and 3month follow up was not statistically significant $(p=0.300)$ but the change observed among the two other times compared was statistically significant $(\mathrm{p}<0.001)$ (Table 8).

Table 7. Change in Weight Following Intervention Administration in the Intervention Group

\begin{tabular}{|l|l|l|l|l|}
\hline \multirow{2}{*}{ Weight } & \multicolumn{2}{|l|}{ Frequency } & Change in \% & p-value \\
\cline { 2 - 3 } & $\mathbf{N}(\%)$ & & \\
\hline & Baseline & 3-month follow up & & \\
\hline$>25 \mathrm{~kg}$ & $1(0.8)$ & $1(0.8)$ & & \\
\hline $26-50 \mathrm{~kg}$ & $40(32.8)$ & $38(31.1)$ & & \\
\hline $51-75 \mathrm{~kg}$ & $72(59.0)$ & $72(59.0)$ & & \\
\hline $75-100 \mathrm{~kg}$ & $9(9)$ & $7(5.7)$ & -3.3 & $0.001^{\text {a* }}$ \\
\hline Total & $\mathbf{1 2 2}$ & $\mathbf{1 1 8}$ & & \\
\hline & Baseline & $\mathbf{6 - m o n t h}$ follow up & & \\
\hline$>25 \mathrm{~kg}$ & $1(0.8)$ & $0(0.0)$ & & \\
\hline $26-50 \mathrm{~kg}$ & $40(32.8)$ & $32(26.2)$ & & \\
\hline $51-75 \mathrm{~kg}$ & $72(59.0)$ & $72(59.0)$ & & \\
\hline $75-100 \mathrm{~kg}$ & $9(9)$ & $9(7.4)$ & -1.6 & $0.001^{\text {a* }}$ \\
\hline Total & $\mathbf{1 2 2}$ & $\mathbf{1 1 3}$ & & \\
\hline & $\mathbf{3 - m o n t h ~ f o l l o w ~ u p ~}$ & $\mathbf{6 - m o n t h}$ follow up & & \\
\hline
\end{tabular}




\begin{tabular}{|l|l|l|l|l|}
\hline$>25 \mathrm{~kg}$ & $1(0.8)$ & $0(0.0)$ & & \\
\hline $26-50 \mathrm{~kg}$ & $38(31.1)$ & $32(26.2)$ & & \\
\hline $51-75 \mathrm{~kg}$ & $72(59.0)$ & $72(59.0)$ & & \\
\hline $75-100 \mathrm{~kg}$ & $7(5.7)$ & $9(7.4)$ & 1.7 & $0.007^{\text {a } *}$ \\
\hline Total & $\mathbf{1 1 8}$ & $\mathbf{1 1 3}$ & & \\
\hline
\end{tabular}

${ }^{a}$ p-value was calculated using McNemar's Test

*significant at $<0.05$

Table 8. Change in Weight Following Intervention Administration in the Control Group

\begin{tabular}{|c|c|c|c|c|}
\hline \multirow[t]{3}{*}{ Weight } & \multicolumn{2}{|l|}{ Frequency } & \multirow[t]{3}{*}{ Change in \% } & \multirow[t]{2}{*}{ p-value } \\
\hline & \multicolumn{2}{|l|}{$\mathbf{N}(\%)$} & & \\
\hline & Baseline & 3-month follow up & & \\
\hline$>25 \mathrm{~kg}$ & $1(0.8)$ & $1(0.8)$ & & \\
\hline $26-50 \mathrm{~kg}$ & $40(32.8)$ & $38(31.1)$ & & \\
\hline $51-75 \mathrm{~kg}$ & $72(59.0)$ & $72(59.0)$ & & \\
\hline $75-100 \mathrm{~kg}$ & $9(9)$ & $7(5.7)$ & -3.3 & $0.300^{\mathrm{a}}$ \\
\hline \multirow[t]{2}{*}{ Total } & 122 & 118 & & \\
\hline & Baseline & 6-month follow up & & \\
\hline$>25 \mathrm{~kg}$ & $1(0.8)$ & $0(0.0)$ & & \\
\hline $26-50 \mathrm{~kg}$ & $40(32.8)$ & $32(26.2)$ & & \\
\hline $51-75 \mathrm{~kg}$ & $72(59.0)$ & $72(59.0)$ & & \\
\hline $75-100 \mathrm{~kg}$ & $9(9)$ & $9(7.4)$ & -1.6 & $0.001^{\mathrm{a} *}$ \\
\hline \multirow{2}{*}{ Total } & 122 & 113 & & \\
\hline & 3-month follow up & 6-month follow up & & \\
\hline$>25 \mathrm{~kg}$ & $1(0.8)$ & $0(0.0)$ & & \\
\hline $26-50 \mathrm{~kg}$ & $38(31.1)$ & $32(26.2)$ & & \\
\hline $51-75 \mathrm{~kg}$ & $72(59.0)$ & $72(59.0)$ & & \\
\hline $75-100 \mathrm{~kg}$ & $7(5.7)$ & $9(7.4)$ & 1.7 & $0.001^{\mathrm{a}^{*}}$ \\
\hline Total & 118 & 113 & & \\
\hline
\end{tabular}

ap value was calculated using McNemar's Test

*significant at $<0.05$

\section{Change in CD4 Cell Count after Intervention}

The mean (SD) CD4 cell count at baseline for the intervention group and control group were $498.92 \quad(168.851)$ and 497.07 (217.561) respectively. After 3 months, the recorded mean (SD) was 498.92 (168.851 for the intervention group (Table 4.39) and 497.07 (217.561) for the control (Table 9). The mean (SD) of the CD4 cells had increased by the 6th months to 587.47 (146.675) in the intervention group and 541.26 (190.366) in the control group. The increase in the mean of CD4 cells from baseline to 6-month follow-up indicates that the intervention on SMS and call reminders helped in improving the CD4 cell count and general clinical outcome of the HIV-positive patients on antiretroviral therapy.

Table 9: Summary of Descriptive of CD4 Cell Count at Baseline, 3 Months Follow up and 6 Months for Control and Intervention Groups

\begin{tabular}{|l|l|l|l|l|}
\hline \multirow{2}{*}{ Time } & \multicolumn{2}{|l|}{ Control } & \multicolumn{2}{l|}{ Intervention } \\
\cline { 2 - 5 } & $\mathbf{N = 1 1 3}$ & $\mathbf{N}=\mathbf{1 1 9}$ & \\
\cline { 2 - 5 } & $\mathbf{X}(\mathbf{S E})$ & $\mathbf{\pm S D}$ & $\mathbf{X}(\mathbf{S E})$ & $\mathbf{\pm S D}$ \\
\hline Baseline & $497.07(20.466))$ & 217.561 & $498.92(15.479)$ & 168.851 \\
\hline 3 months follow up & $497.07(20.466)$ & 217.561 & $498.92(15.479)$ & 168.851 \\
\hline 6 months follow up & $541.26(17.908)$ & 190.366 & $587.47(13.446)$ & 146.675 \\
\hline
\end{tabular}

SD standard deviation

$\mathrm{X}$ Mean 
Using paired t-test for the analysis: Comparing baseline and 6-month follow-up results, there was a difference in mean of CD4 count between control and intervention group at 6 months follow up. The immunological response was better in the intervention group at 6-month follow-up (mean \pm SD = $88.555 \pm 73.289$ ) (Table 10). The change in the
CD4 count was statistically significant $(\mathrm{t}(231)=$ -13.181; $\mathrm{p}$ <0.01). There was a change in CD4 in the control group as well, but the level of change was not as much as the change observed in the intervention group. (Table 10) Overall, this suggests that phone reminders elicited a change in the level of CD4 count among HIV patients.

Table 10. Paired Sample T-Test of CD4 Count in the Intervention and Control Group

\begin{tabular}{|l|l|l|l|l|l|l|}
\hline Pair & Mean & SE & SD & df & t & P -value \\
\hline Intervention \\
\hline Baseline vs 6 months & -88.555 & 6.718 & 73.289 & 118 & -13.181 & 0.001 \\
\hline Control & & & \\
\hline Baseline vs 6 months & -44.186 & 6.810 & 72.394 & 112 & -6.488 & 0.001 \\
\hline
\end{tabular}

*significant at $<0.05$

\section{Change in Proportion of Tuberculosis and Other Opportunistic Infections}

The participants who had other opportunistic infections in the intervention group were 14 at baseline (Table 11) and by the 3-month and 6month follow-up period, there were only 8 and 5 HIV-positive patients with confirmed opportunistic infection respectively. This indicates that the intervention was effective in reducing the presence of opportunistic infections among HIV positive patients on antiretroviral therapy and subsequently improving clinical outcome in the respondents. At the 3-month follow-up assessment, the number of patients who had opportunistic infections had increased to 22 from 20 in the control group. The 6-month follow-up assessment shows (Table 12) that at 6month follow-up, there was a $6.5 \%$ decrease in the proportion of patients with opportunistic infections.

Table 11. Change in Proportion of Participants with Tuberculosis and other Opportunistic Infections in the Intervention Group

\begin{tabular}{|c|c|c|c|c|c|c|c|}
\hline Items & \multicolumn{2}{|c|}{ Baseline } & \multicolumn{2}{|c|}{ 3-month follow up } & \multicolumn{2}{|c|}{ 6-month follow up } & p-value \\
\hline \multicolumn{8}{|l|}{ Tuberculosis } \\
\hline No sign of symptom of TB & 68 & 55.7 & 76 & 62.3 & 74 & 60.7 & \multirow[t]{6}{*}{$0.735^{\mathrm{a}}$} \\
\hline Presumptive TB & 16 & 13.1 & 10 & 8.2 & 3 & 2.5 & \\
\hline Currently on Isoniazid & 32 & 26.2 & 29 & 23.8 & 34 & 27.9 & \\
\hline Confirmed TB case & 4 & 3.3 & 1 & 0.8 & 0 & 0 & \\
\hline TB treatment & 2 & 1.6 & 5 & 4.1 & 8 & 6.6 & \\
\hline Total & 122 & 100 & 121 & 99.2 & 119 & 97.5 & \\
\hline \multicolumn{8}{|c|}{ Presence of Opportunistic Infections } \\
\hline No & 108 & 88.5 & 113 & 92.6 & 114 & 93.4 & \multirow[t]{3}{*}{$0.064^{\mathrm{a}}$} \\
\hline Yes & 14 & 11.5 & 8 & 6.6 & 5 & 4.1 & \\
\hline Total & 122 & 100 & 121 & 992 & 119 & 975 & \\
\hline
\end{tabular}

${ }^{a} \mathrm{p}$ value was calculated using McNemar's Test

*significant at $<0.05$ 
Table 12: Change in Proportion of Participants with Tuberculosis and other Opportunistic Infections in the Control Group

\begin{tabular}{|c|c|c|c|c|c|c|c|}
\hline Items & \multicolumn{2}{|c|}{ Baseline } & \multicolumn{2}{|c|}{ 3-month follow up } & \multicolumn{2}{|c|}{ 6-month follow up } & p-value \\
\hline \multicolumn{8}{|l|}{ Tuberculosis } \\
\hline No sign of symptom of TB & 89 & 73.0 & 67 & 54.9 & 58 & 47.5 & \multirow[t]{6}{*}{$0.128^{\mathrm{a}}$} \\
\hline Presumptive TB & 11 & 9.0 & 9 & 7.4 & 7 & 5.7 & \\
\hline Currently on Isoniazid & 17 & 13.9 & 34 & 27.9 & 34 & 27.9 & \\
\hline Confirmed TB case & 4 & 3.3 & 5 & 4.1 & 4 & 3.3 & \\
\hline TB treatment & 1 & 0.8 & 3 & 2.5 & 10 & 8.2 & \\
\hline Total & 122 & 100 & 118 & 96.7 & 113 & 92.6 & \\
\hline \multicolumn{8}{|c|}{ Presence of Opportunistic Infections } \\
\hline No & 102 & 83.6 & 96 & 78.7 & 99 & 81.1 & \multirow[t]{3}{*}{$0.912^{\mathrm{a}}$} \\
\hline Yes & 20 & 16.4 & 22 & 18.0 & 14 & 11.5 & \\
\hline Total & 122 & 100 & 118 & 96.7 & 113 & 92.6 & \\
\hline
\end{tabular}

${ }^{a} \mathrm{p}$ value was calculated using McNemar's Test

*significant at $<0.05$

\section{Discussion}

\section{Socio-demographic Characteristics of the Respondents}

The findings of this study show that more participants were middle-aged with about twothirds between the ages $26-45$ years. This distribution was observed in both the control and intervention groups and similar findings were reported in a study carried out in the southwestern region of Nigeria [13]. Also, more patients attending antiretroviral clinics in Nigeria were reported to be between the ages 18-40 years [14]. There was no statistically significant relationship between gender and adherence in this study, these findings are similar in studies conducted and reported in many countries [6,15-23]. Marital status had an insignificant role on participants' medication adherence, and this is in line with the findings from study conducted in Brazil [24] and United State [26], however reported that marital status had an association with adherence.

\section{Effectiveness of Mobile Phone Reminder on Medication Adherence}

There was an increase in the level of adherence to medication among intervention group after the intervention was administered as compared to the control group where they had a drop in adherence. These corroborate the findings of some studies reported [26-28]. This explains that the intervention program on medication adherence has an effect on the participants.
This study utilized both phone calls and short messaging services to remind the patients of their appointments. The phone calls were placed 3 days before their scheduled clinic days and a SMS was sent out a day to appointment. Similar findings were reported in Kenya [29]. Another study reported significant improvements in adherence and viral suppression among an intervention group that received weekly interactive SMS (inquiring about health and well-being), with follow-up calls after 48 hours [30].

Further evidence to support on the importance of reminders are available from reports in literature. A study conducted in USA made recommendations for the use of programmable electronic medication reminders to increase quality of cues to reduce forgetfulness among patients and thereby improve adherence to medications [31]. RCT study conducted in Nairobi, Kenya, the use of digital reminders was not found to influence the adherence to ART among the patients. The study utilized an early adherence intensive counseling and compared the effects of the counseling to the effects from the use of digital reminders [32] Also, in Kenya, another study reported a larger proportion of adherent participants exposed to SMS reminders in comparison to controls [29].

\section{Effectiveness of Mobile Phone Reminders on Clinic Attendance}

The mobile phone reminder intervention had a change in the frequency of clinic attendance of the patients. After 3 months follow-up, there was a high frequency of attendance in the 
intervention group, but this frequency was not statistically significant. This implies that the recorded figures could have been as a result of factors other than the intervention. At 6-month follow-up, the observed frequency was increased, and this was statistically significant. This indicates that the intervention influenced the patients' clinic attendance. In a study conducted in Malaysia, the findings showed that the intervention produced a higher proportion of regular clinic attendees and a lower proportion of missed appointments [33]. Also, another study conducted in Uganda reported lower missed clinic attendance among the patients recruited for the study and this corresponded to improved adherence [34].

\section{Effectiveness of Mobile Phone Reminder on Treatment Outcomes}

The clinical outcomes measured among the patients were their weight, CD4 cell count, presence of tuberculosis and other opportunistic infections. The mobile phone reminder intervention proved to be effective in changing the levels of the desired variables.

Change in participant weight: The study findings showed that there was a change in the weight mean after the mobile phone reminder intervention. The changes in mean weight across the three time periods were statistically significant. The control group which had no intervention administered recorded some slight increase in weight also after the study, but there was no statistical basis for the change recorded. This finding indicates that the intervention was effective in improving the clinical outcome among the patients attending ART clinics in Adamawa State.

Few studies have established the relationship between medication adherence and weight of respondents. The findings of this study were similar to findings by researchers from SubSaharan Africa, Kenya and Rwanda specifically [35]. The study tested the short- and long-term effect of the Modified Directly Observed Antiretroviral Treatment among infected individuals. The result showed that there was an impact of the intervention on the weight of the PLWHAs. Also, study conducted in Rwanda reported weight increase [36]. Despite the same follow-up period of 6-months as reported by this present study and study conducted in Malaysia, the latter showed no positive effect of the intervention on the weight of participants and the differing results could be as a result of the influence of socio-demographic factors of the participants [33].

Change in CD4 cell count: The findings of this study showed that there was a significant rise in CD4 count in the intervention group after six months follow up. At three months, the rise was little, but by the sixth month postintervention, there was a highly significant rise in the mean (from 496.38 cells $/ \mathrm{mm}^{3}$ to 587.47 cells $/ \mathrm{mm}^{3}$ ). Similar results to those observed in this study were reported by Abdulrahman et al., 2017 in a study carried out in Malaysia. A report of the study conducted in Nigeria is also in agreement with the findings of this present study [14]. They recorded a mean rise in CD4 count among adherent patients at one-year follow-up compared to the non-adherent group. The lower counts of CD4 cell observed in this study could be due to the shorter follow-up period of 6 months compared to the 12 months [14]. Higher CD4 count was reported in among the participants in United State of America after a 12-month follow-up period [37]. Another related study in South Africa reported higher CD4 changes and greater viral load suppression in their patients [38].

Compelling evidence on the association between CD4 count and adherence levels have been established in several studies. Individual interventions or program-level interventions that are designed and targeted to improve ARV medication adherence among patients would invariably produce a positive impact on immunologic response (CD4 count) to treatment.

Change in Tuberculosis and other Opportunistic Infections: There was an increase in the proportion of patients who had no signs of tuberculosis at 3 months follow up. This is an indication that the use of the medications reduced some clinical outcomes by reminding the HIV-positive patients of their drug regimen and clinic appointments. In the control group also, there was a decrease in the proportion of participants who had no sign and symptom of tuberculosis from baseline to 6-month followup. The change in proportion observed in the two groups were however not statistically significant. This indicates that the change could have been due to some other factors which were not related to the mobile phone reminder. 
Finding of this study shows a decrease in the proportion of participants who had no sign and symptom of tuberculosis from baseline to 6month follow-up. The change in proportion observed in the two groups were however not statistically significant. Similar findings were reported in Brazil [39, 40]. In Malaysia, a significant decrease in the proportion of patients in the intervention group who were tuberculosis suspects was reported [33].

\section{Limitations}

The result of the improve patient's adherence was obtained through self-report and pill count, therefore, the quality of the data obtained from pill counting could be affected because some clients may discard tablets not taken prior to their routine clinic visit, that can lead to overestimated adherence.

Unannounced patients home visit pills count, which may be more accurate could not be conducted due to limited resources and issues of confidentiality and stigma in the community.

Self-report is subjected to recall bias, and that may affect the quality of the results of the study.

Due to budget constraints, viral loads could not be monitored even though it is considered to

\section{References}

[1] Joint United Nation Programme on HIV/AIDS (UNAIDS, 2018). Global HIV \& AIDS statistics. 2018 fact sheet. http://www.unaids.org/en/resources/fact-sheet).

[2] National Agency for Control of AIDS (NACA) (2017). 'National Strategic Framework on HIV and AIDS: $2017 \quad-2021 . \quad$ Page 6-16 https://www.childrenandaids.org/sites/default/files/2 01711/NATIONAL-HIV-AND AIDS-STRATEGIC FRAMEWORK.pdf.

[3] National HIV Sero-prevalence Sentinel Survey (NHSS 2014).

[4] Bekele Belayihun1 and Rahma Negus (2015). Antiretroviral Treatment Adherence Rate and Associated Factors among People Living with HIV in Dubti Hospital, Afar Regional State, East Ethiopia. Hindawi Publishing Corporation International Scholarly Research Notices Volume 2015, Article ID 187360, 5 pages. http://dx.doi.org/10.1155/2015/187360.

[5] World Health Organization. (WHO, 2005) Interim WHO clinical staging of HIV/AIDS and HIV/AIDS case definitions for surveillance: African region. be the gold standard for monitoring adherence and confirming treatment response.

Also, short duration of the study (6 months) follow-up may have resulted in adherence estimates and retention that represent the bestcase scenario evidence and not necessarily an accurate estimate.

\section{Conclusion}

The findings of this study have established that simple technologies such as a phone call or short messaging service (SMS) could be an important strategy to sustain or increase levels of medication adherence, improved clinic attendance and clinical outcomes among HIVinfected individuals on antiretroviral therapy.

\section{Acknowledgments}

The authors would like to acknowledge the hospital management and entire ART Unit staff of the FMC Yola, Specialist Hospital Yola, St Francis Jambutu, GH Mubi and GH Mayo Belwa. Also acknowledged the contributions of all the members of the research team toward the success of this study.

Switzerland:

https://www.who.int/hiv/pub/guidelines/clinicalstagi ng.pdf.

[6] Paterson DL, Swindells S, Mohr J, Brester M, Vergis EN, Squier C, et al. (2002) Adherence to protease inhibitor therapy and outcomes in patients with HIV infection. Annals of internal medicine. 2000;133(1):21-30. pmid:10877736.

[7] Suleiman IA, Momo A. Adherence to antiretroviral therapy and its determinants among persons living with HIV/AIDS in Bayelsa state, Nigeria. Pharmacy Practice 2016 Jan-Mar;14(1):631. doi: 10.18549/PharmPract.2016.01.631.

[8] Kelley LL' Engle, Kimberly Green MA, Stacey M Succop et al., (2015). Scaled-Up Mobile Phone Intervention for HIV Care and Treatment: Protocol for a Facility Randomized Controlled Trial. JMIR Res Protoc 2015;4(1): e11) doi:10.2196/resprot.3659 https://www.ncbi.nlm.nih.gov/pmc/articles/PMC431 9075/.

[9] National Guideline for HIV Prevention Treatment and Care (2016)- Nigeria. http://apps.who.int/medicinedocs/documents/s23252 en/s23252en.pdf. 
[10] President Emergency Plan for AIDS Relief (PEPFAR) (2016). Country/Regional Operational Plan (COP/ROP) 2016 guidance. Office of the U.S. Global AIDS Coordinator, Washington, D.C.: OGAC;2015.

[11] World Health Organization (WHO, 2015). Guideline on when to start antiretroviral therapy and on pre-exposure prophylaxis for HIV. Geneva: World Health Organization 2015 (http://www.who.int/hiv/pub/guidelines/earlyrelease -arv/en.

[12] Lemeshow S, David W. Ho, J Klar, S K. Lwanga and World Health Organization (1990). Adequacy of sample size in health studies. WHO IRIS: 239. http://www.who.int/irs/handle/10665/41607.accesse d.

[13] Olowookere, S.A., Fatiregun, A.A, Ladipo, M.M.A, Abioye-Kuteyi, E.A. \& Adewole, I.F. (2016). Effects of adherence to antiretroviral therapy on body mass index, immunological and virological status of Nigerians living with HIV/AIDS. Alexandria Journal of Medicine (2016) 52, 51-54.

[14] Anoje, C., Agu, K.A., Oladele, E.A., Badru, T., Adedokun, O., Oqua, D., Khamofu, H., Adebayo, O., Torpey, K., Chabikuli, O.N. (2017). Adherence to On-Time ART Drug Pick-Up and Its Association with CD4 Changes and Clinical Outcomes Amongst HIV Infected Adults on First-Line Antiretroviral Therapy in Nigerian Hospitals AIDS Behav. 2017 Feb;21(2):386-392. doi: 10.1007/s10461-016-1473$\mathrm{z}$.

[15] Applebaum AJ, Richardson MA, Brady SM, Brief DJ, keane TM (2009). Gender and Other psychosocial factors as predictors of adherence to HAART in adults with comorbid HIV/aids, psychiatric and substance related disorder. Aids Behav. ;13(1):60-5.

[16] Carrieri MP, Chesney MA, Spire B, et al. (1999). Failure to maintain adherence to HAART in a cohort of French HIV-positive injecting drug users. Int $\mathrm{J}$ Behav Med. 2003; 10:1-14.8. Holzemer WL, Corless IB, Nokes KM, et al (2000). Predictors of selfreported adherence in persons living with HIV disease. AIDS Patient Care STDS.13:185-97.9.

[17]Bouhnik AD, Chesney M, Carrieri $\mathrm{P}$, et al. (2002) Non adherence among HIV-infected injecting drug users: the impact of social instability. J Acquire Immune Defic Syndr. ;31(suppl 3): S149 -S153.10.

[18] Golin CE, Liu H, Hays RD, et al. (2002). A prospective study of predictors of adherence to combination antiretroviral medication. $\mathrm{J}$ Gen InternMed. 2002; 17:756 - 65.11.
[19] Gordillo V, del Amo J, Soriano V, GonzalezLahoz J. (1999) Socio demo-graphic and psychological variables influencing adherence to antiretroviral therapy. AIDS.13:1763-9.12.

[20]Chesney, M.A. (2000). Factors affecting adherence to antiretroviral therapy. Clinical Infectious Disease 2000; 30 S171-S76.

[21]Eldred LJ, Wu AW, Chaisson RE, Moore RD (1998) Adherence to antiretroviral and pneumocystis prophylaxis in HIV disease. J Acquired Immune Defic Syndr Hum Retrovirol.; 18:117-25.5.

[22] Moatti J.P, Carrieri M.P, Spire B, Gastaut J.A, Cassuto J.P, Moreau J. (2000) Adherence to HAART in French HIV-infected injecting drug users: the contribution of buprenorphine drug maintenance treatment. The Manif 2000 study group. AIDS. 2000; 14:151-5.6.

[23] Wagner, G.J. (2002). Predictors of antiretroviral adherence as measured by self-report, electronic monitoring, and medication diaries. AIDS Patient Care STDS. 16:599 - 608.

[24] Nduaguba, S.O., Soremekun, R.O., Olugbake, O.A., \& Barner, J.C (2017). The relationship between patient-related factors and medication adherence among Nigerian patients taking highly active antiretroviral therapy. Africa Health Science. 17(3): 738745.

[25]Bonolo, P.F., Ceccato, M.B., Rocha, G. M., Acúrcio, F.A., Campos, L. N., \& Guimarães, M. C. (2013). Gender differences in non-adherence among Brazilian patients initiating antiretroviral therapy. Clinics (Sao Paulo). 68, 612-620.

[26] Simoni, J.M., Pearson, C.R., Pantalone, D.W., et al. (2006) Efficacy of interventions in improving highly active antiretroviral therapy adherence and HIV-1 RNA viral load. A meta-analytic review of randomized controlled trials. Journal Acquired Immune Deficiency Syndrome 43(Suppl 1): S23S35.

[27] Wagner, G.J, Kanouse, D.E., Golinelli, D., et al (2006). Cognitive-behavioral intervention to enhance adherence to antiretroviral therapy: a randomized controlled trial (CCTG 578) AIDS 20:1295-1302.

[28] Carrico, A.W, Antoni, M.H., Duran, R.E., et al. (2006). Reductions in depressed mood and denial coping during cognitive behavioral stress management with HIV-positive gay men treated with HAART. Annual Behavior Medicine 31:155-164.

[29] Pop-Eleches C, Thirumurthy H, Habyarimana JP, Zivin JG, Goldstein MP, de Walque D, et al. (2011). Mobile phone technologies improve adherence to antiretroviral treatment in a resource- 
limited setting: a randomized controlled trial of text message reminders. AIDS. 2011;25(6):825-34. pmid:21252632.

[30]Lester RT, Ritvo P, Mills EJ, Kariri A, Karanja S, Chung MH, et al. (2010). Effects of a mobile phone short message service on antiretroviral treatment adherence in Kenya (WelTel Kenya1): a randomized trial. Lancet. 2010;376(9755):1838-45. pmid:21071074 [doi:10.1016/S01406736(10)61997-6].

[31] Woods SP, Moran LM, Carey CL, Dawson MS, Iudicello JE, et al. (2008) Prospective memory in HIV infection: is "remembering to remember" a unique predictor of self-reported medication management? Arch Clin Neuropsychology 23:257270.

[32]Chung MH, Richardson BA, Tapia K, BenkiNugent S, Kiarie JN, Simoni JM, et al. (2011). A randomized controlled trial comparing the effects of counseling and alarm device on HAART adherence and virologic outcomes. PLoS Medicine. 2011;8(3): e1000422. pmid:21390262.

[33] Abdulrahman SA, Rampal L, Ibrahim F, Radhakrishnan AP, Kadir Shahar H, Othman N (2017) Mobile phone reminders and peer counseling improve adherence and treatment outcomes of patients on ART in Malaysia: A randomized clinical trial. PLoS ONE 12(5): e0177698. https://doi.org/10.1371/journal.pone.0177698.

[34] Kunutsor S, Walley J, Katabira E, Muchuro S, Balidawa H, Namagala E, et al. Using mobile phones to improve clinic attendance amongst an antiretroviral treatment cohort in rural Uganda: A cross-sectional and prospective study. AIDS Behav. 2010; $\quad$ 14(6): $1347 \pm 1353$. https://doi.org/10.1007/s10461-010-9780-2 PMID: 20700644.
[35] Sarna A, Luchters S, Geibel S, Chersich MF, Munyao P, Kaai S, et al. Short-and long-term efficacy of modified directly observed antiretroviral treatment in Mombasa, Kenya: a randomized trial. J Acquir

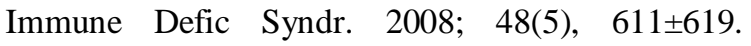
https://doi.org/10.1097/QAI.0b013e3181806bf1 PMID: 18645509.

[36] Rich ML, Miller AC, Niyigena P, Franke MF, Niyonzima JB, Socci A, et al. (2012). Excellent Clinical Outcomes and High Retention in Care among Adults in a Community-Based HIV Treatment Program in Rural Rwanda J Acquire Immune Defic

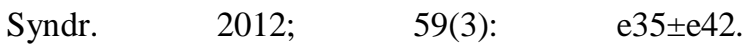
https://doi.org/10.1097/QAI.0b013e31824476c4 PMID: 22156912.

[37] Mannheimer S, Friedland G, Matts J, Child C, Chesney M. The consistency of adherence to antiretroviral therapy predicts biologic outcomes for human immunodeficiency virus infected persons in clinical trials. Clin Infect Dis. 2002; 34:1115-21.

[38] El-Khatib Z, Ekstrom AM, Coovadia A, Abrams EJ, Petzold M, et al. (2011) Adherence and virologic suppression during the first 24 weeks on antiretroviral therapy among women in Johannesburg, South Africa - a prospective cohort study. BMC Public Health 11: 88.

[39] Sampaio-Sa M, Page-Shafer K, Bangsberg DR, et al. $100 \%$ adherence study: educational workshops vs video sessions to improve adherence among ARTnaive patients in Salvador, Brazil. AIDS Behaviour. 2008;12(4 Suppl): S54-S62.

[40] Garcia R, Ponde M, Lima M, Souza AR, Stolze SM, Badaro R. Lack of effect of motivation on the adherence of HIV-positive/AIDS patients to antiretroviral treatment. Braz J Infect Dis. 2005;9(6):494-499. 